\title{
FEM ANALYSIS OF THE FORGING PROCESS OF HUB PART FROM AZ80 MAGNESIUM ALLOY
}

\author{
A. Gontarz ${ }^{1}$, Z. Pater ${ }^{1}$, K. Drozdowski ${ }^{2}$, A. Tofil ${ }^{1}$, J. Tomczak $^{1}$ \\ ${ }^{1}$ Mechanical Engineering Faculty, Lublin University of Technology, Poland \\ (a.gontarz@pollub.pl) \\ ${ }^{2}$ ZOP Co. Ltd Forging Plant, Poland
}

\begin{abstract}
The results of theoretical analysis of metal forming process of hub forging from AZ80 magnesium alloy are presented in this paper. Calculations were made with the application of commercial software based on finite element method. Simulations were conducted for two technologies of forging: on a die hammer and on a hydraulic press. Kinematics of material flow, strains, temperature and fracture criterion according to Cockroft-Latham were analyzed. Forging force in the case of press usage and impact energy in the case of hammer usage were calculated as well. On the basis of the obtained results, the analysis of limiting phenomena, which could appear during the process, was made. These phenomena include: possibility of overlapping presence, not filling of die impression, overheating of material and cracks. On the basis of calculations of forces and energy necessary for forming, required parameters of forging machines were chosen. Theoretical verification of hub part forging technology allowed to state that it is possible to obtain final product of assumed quality. The results of calculations provided the basis for planning of experimental tests in industrial conditions.
\end{abstract}

Keywords: Forging process, Press, Hammer, AZ80 magnesium alloy.

\section{INTRODUCTION}

This paper deals with numerical verification of the forming technology of a hub wheel forming from magnesium alloy AZ80. Application of this part in the design of small planes will allow for reduction of their mass. The authors of this paper have decided to manufacture of such a part in industrial conditions. The first stage of the work was connected with working out of drop forging outline, forging technologies and heat treatment technologies. The next stage dealt with numerical verification, presented in this paper, of the worked out technology. Later, drop forging and a finished part manufacturing in industrial conditions is foreseen and the product passing for the further certification and permission for implementation in planes construction is considered. 


\section{FORGING TECHNOLOGY CHARACTERISTIC}

Design of drop forging (Fig. 1) was the first stage of technology design. On the basis of the authors' industrial experience and information taken from specialist literature $[1 \div 3]$, two variants of forging technology of a wheel hub forging were worked out. The difference is based on the application of various forging machines used in the process. Two machines were considered: die hammer and hydraulic press. Assuming of such forging devices resulted from the necessity of checking of forging process with large strain rate (forging on hammer) and small strain rate (forging on hydraulic press). In the case of obtaining a proper product at the application of both forging machines, the number of potential plants which can produce hub will be larger.

The technological process consists of the following operations:

- material cutting to the dimension $\varnothing 100 \mathrm{~mm} \times 93 \mathrm{~mm}$,

- heating of the billet to the temperature of the forging beginning equal $410^{\circ} \mathrm{C}$,

- upsetting and preliminary operation of forging (in the case of forging on hammer the operation should be done using $1 \div 5$ strokes),

- heating of the preform to the temperature of the forging beginning equal $410^{\circ} \mathrm{C}$,

- final operation of forging in die impression (in the case of forging on hammer 4 blows were assumed).
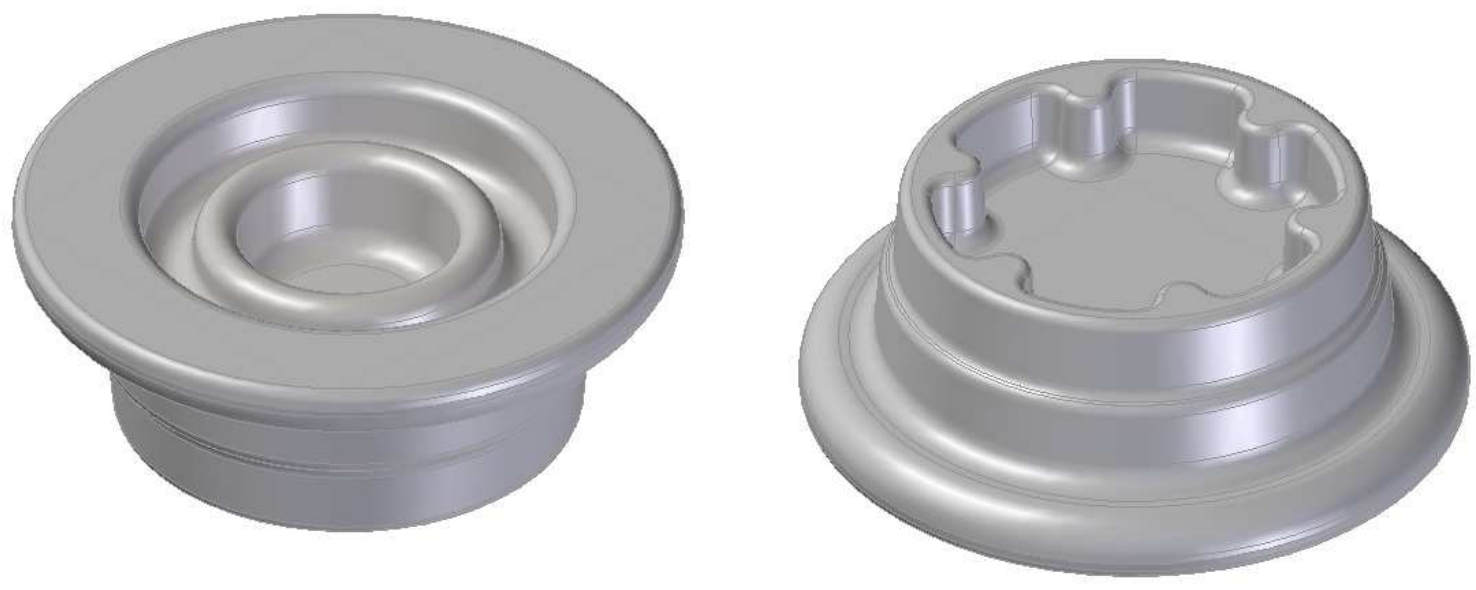

Figure 1. Design of a hub forging from AZ80 magnesium alloy.

\section{THEORETICAL VERIFICATION OF THE FORGING TECHNOLOGY}

The software DEFORM 3D based on finite element method was used in simulations of the designed forging processes. Numerical verification aimed at:

- checking material flow kinematics in particular operations, mainly with consideration of impression filling, overlapping and other shape faults presence,

- calculating of stroke energy (in the case of forging on hammer) and forging force (in the case of forging on the press) in order to choose appropriate forging device,

- determining of forging areas where exists the largest possibility of cracks appearance, 
- analyzing of temperature and strain distribution in the forging.

Simulations precision depends to a large extent on material model, which main part constitutes dependency of yield stresses from strains values at various temperatures and at various strains rates. In the analyzed case, a rigid-plastic material model was assumed, based on research works conducted by scientific team of Silesian University of Technology (Poland) and directed by E. Hadasik (unpublished results). Research works were conducted on plastometer at temperatures of forging heating $250{ }^{\circ} \mathrm{C}, 300{ }^{\circ} \mathrm{C}, 350{ }^{\circ} \mathrm{C}$ and $400^{\circ} \mathrm{C}$ and at strain rates $0.01 \mathrm{~s}^{-1}, 0.1 \mathrm{~s}^{-1}, 1 \mathrm{~s}^{-1}$ and $10 \mathrm{~s}^{-1}$.

In calculations, model of constant friction, characterized by friction factor $m=0.24$, was assumed. Such a value was considered basing on own research results, from which occurs that, depending on research temperature, friction factor assumes values 0.15-0.24 [4]. Taking into account that in industrial conditions lubrication cannot be as precise (on tools whole surface) as in laboratory research works, the limiting scope of friction factor values was assumed. Moreover, heat transfer coefficient between material and tool equal $11000 \mathrm{~W} /\left(\mathrm{m}^{2} \cdot \mathrm{K}\right)$ and heat transfer coefficient between material and environment equal $20 \mathrm{~W} /\left(\mathrm{m}^{2} \cdot \mathrm{K}\right)$ were also assumed [5].

\subsection{Forging process on the hammer}

The first variant of the process which underwent verification was the forging process on hammer at the billet heating temperature $410^{\circ} \mathrm{C}$. The further operations of the process together with strains distributions were given in Fig. 2 and Fig. 3. The character of strains distributions is typical for forging processes on hammer. Larger values are present in the forging upper part, from the striking tool's side. The shape of finished drop forging (Fig. 3b) does not show faults. The billet volume was chosen correctly - flash volume is small; the impression is precisely filled and during forging overlapping does not appear. It is more visible in Fig. 4, in which the drop forging shape from the top and bottom is presented. Hence, it can be stated that the analyzed process guarantees obtaining of product of good geometrical quality.

a)

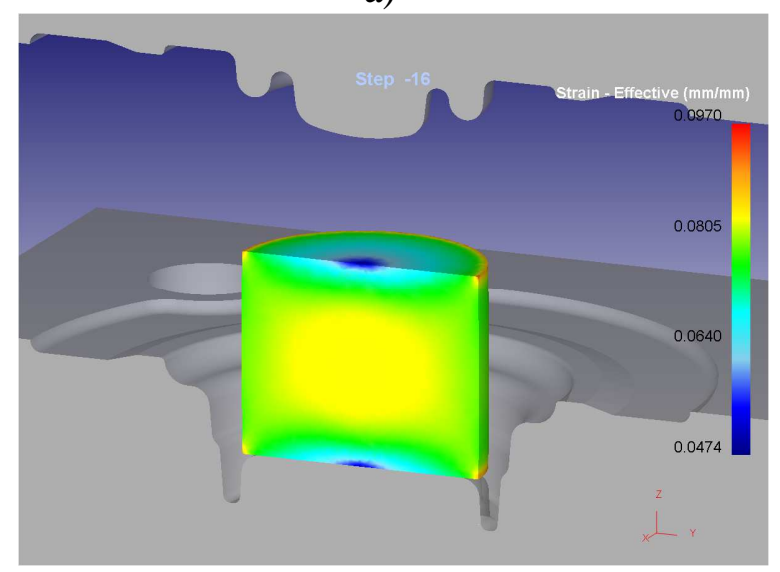

b)

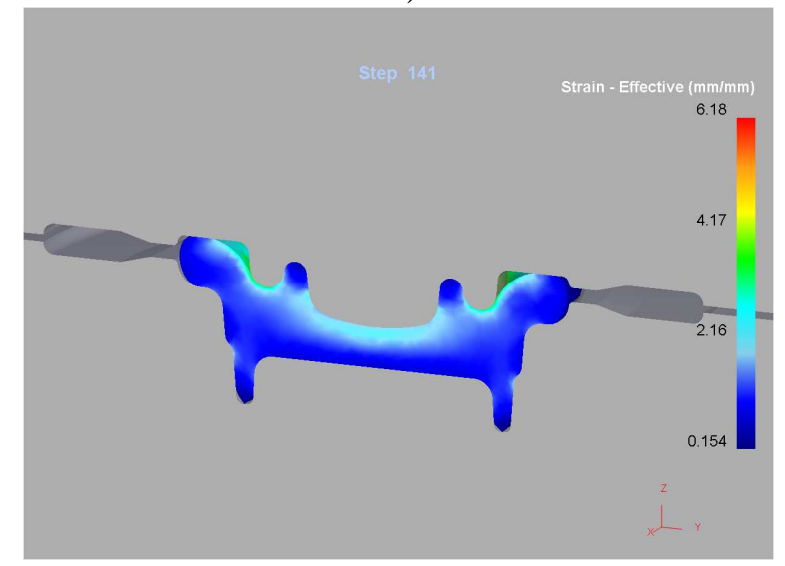

Figure 2. The beginning (a) and the end (b) of the preliminary forging operation in the initial impression together with strains distribution - axial section. 
a)

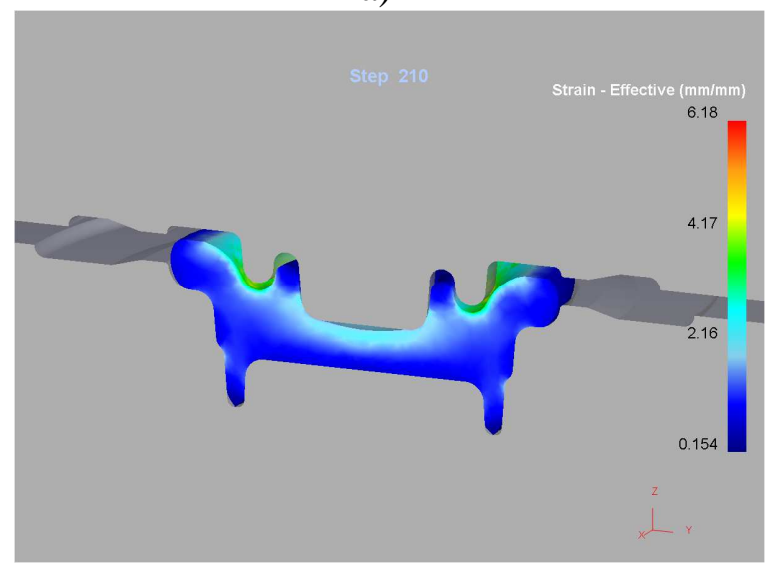

b)

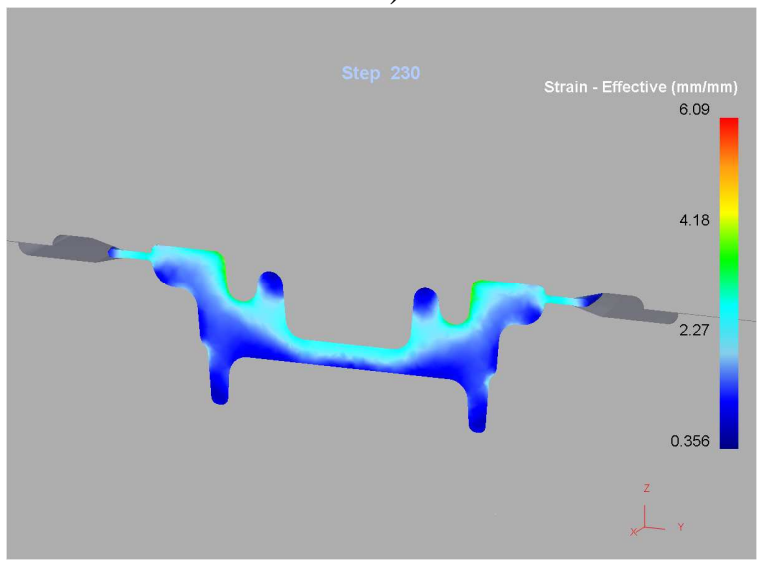

Figure 3. The beginning (a) and the end (b) of the final forging operation in the die impression together with strains distribution - axial section.

a)

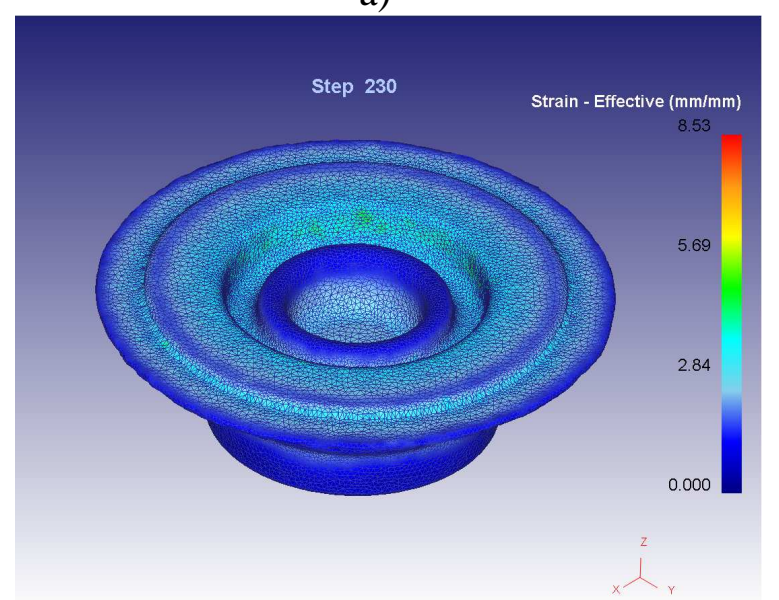

b)

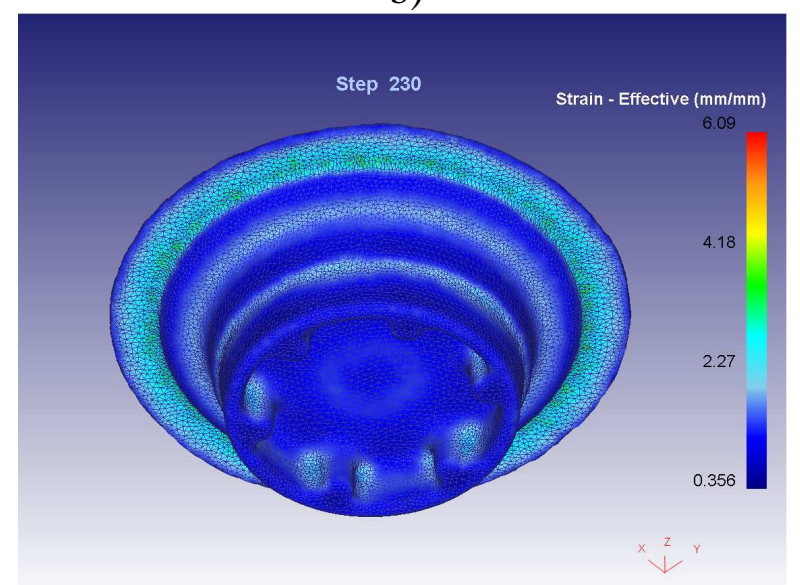

Figure 4. Forging obtained in simulation of the forging process on hammer: a) view from the top, b) view from the bottom.

In the forging process on hammer exists the possibility of cracks presence. Because of that, damage criterion according to Cockroft-Latham (Fig. 5) was analyzed, characterized by integral $(\mathrm{C}-\mathrm{L})$ value calculated from the equation [6]:

$$
C=\int_{0}^{\varepsilon} \frac{\sigma_{1}}{\sigma_{i}} d \varepsilon,
$$

where:

$\sigma_{1}$ - the largest principal stress,

$\sigma_{\mathrm{i}}$ - equivalent stress,

$\varepsilon$ - strain.

In order to determine the cracking moment it is necessary to know the limiting value of the integral described by the equation: 


$$
C_{g r}=\int_{0}^{\varepsilon^{*}} \frac{\sigma_{1}}{\sigma_{i}} d \varepsilon
$$

where:

$\varepsilon^{*}$ - limiting strain of cracking,

the rest of the markings as in equation (1).

The value of the limiting integral depends e.g. on material temperature and strain rate. As it can be seen from research works presented in specialist literature, the integral depends also on state of stress, which constitutes main problem in determining universal limiting value (possible to apply for all processes) [7]. This problem makes precise determining of cracking moment impossible. It is, however, possible to determine areas where the largest danger of cracks presence exists. From Fig. $5 \mathrm{~b}$ results that this is the flash external circumference. In this area are present circumferential tensile stresses, which, as it is known from industrial practice, cause radial cracks. They are not dangerous if they do not influence forging volume. Omitting the flash volume, the largest values C-L integral reaches in the upper part (flange) of both drop forging and perform. It should be noticed that in the case of forging on hammers, cracks appear at the dies splitting line, in the place of forging connection with the flash. Distribution of C-L integral presented in Fig. 5b confirms that this is a dangerous area in the analyzed process. In order to lower the possibility of material cracking in this area, larger number of strokes with smaller energy during forging in die impression should be applied.

a)

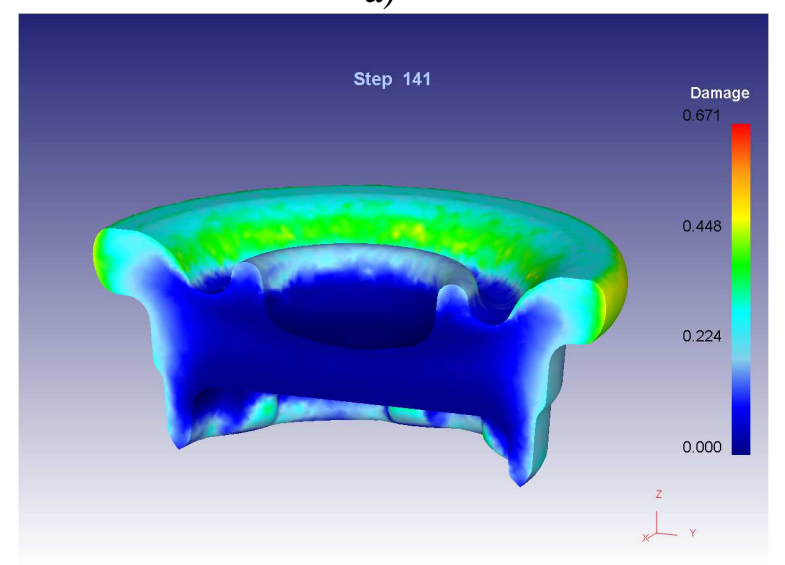

b)

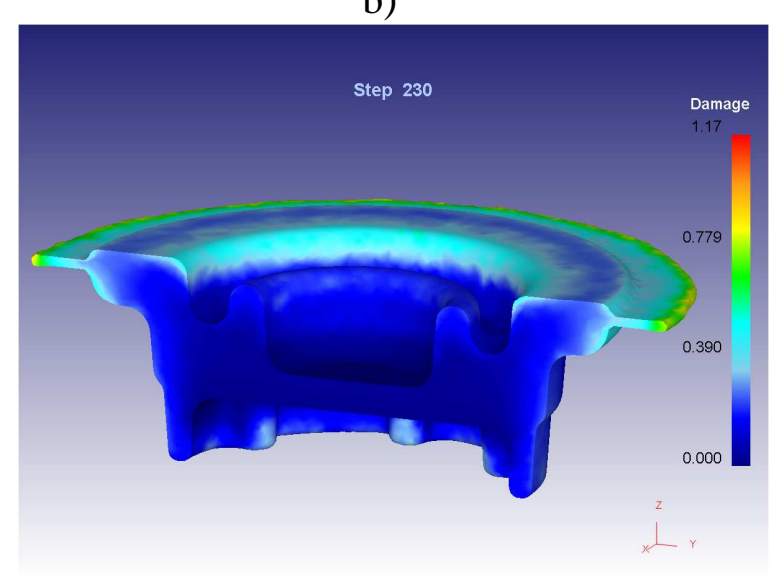

Figure 5. Distribution of Cockroft-Latham integral value in drop forging at the end of the forging process: a) preliminary operation, b) final operation.

Distribution of temperature at the following stages of the process is shown in Fig. 6. As it can be seen in radial caving in the preform (Fig. 6a) and in forging flash (Fig. 6b), the temperature reaches value exceeding $600{ }^{\circ} \mathrm{C}$. In such conditions material will undergo overheating, which disqualifies the product. It should be, however, considered, that such a large temperature can be the result of calculations faults connected with material model limitations, which was worked out on the basis of research works within the scope of $250^{\circ} \mathrm{C} \div 400^{\circ} \mathrm{C}$. This issue should be considered in the planned industrial research works. 
a)

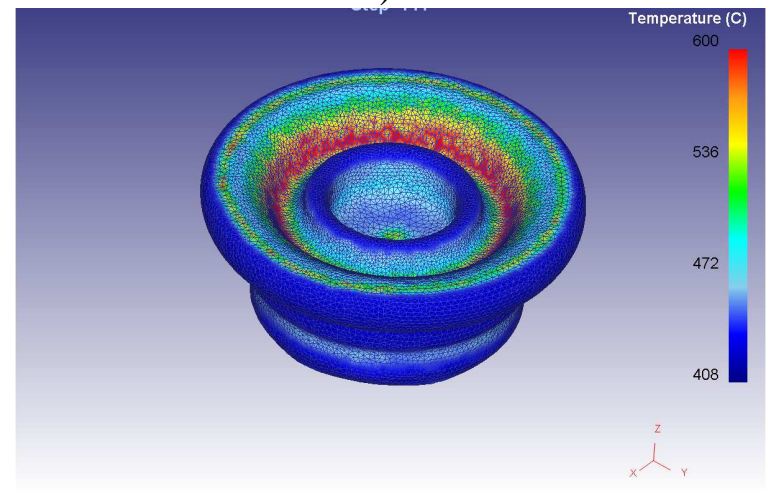

b)

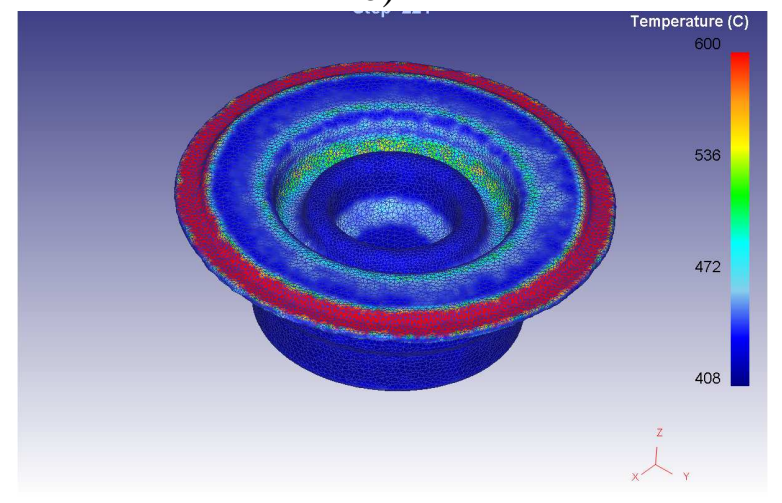

Figure 6. Distribution of temperature at the following stages of the process: a) after preliminary operation, b) after final operation.

Energy consumption in the operations of initial and die forming is presented in Fig. 7. The analysis of the stroke energy showed that at the application of hammer MPM 10000B of stroke energy $110 \mathrm{~kJ}$ and mass of the falling part $3000 \mathrm{~kg}$ in the following operations a particular number of strokes should be applied:

- upsetting can be made at one stroke,

- preliminary forging operation can be made at four strokes with usage of 50\% of energy in each stroke,

- final forging in die impression can be made at five strokes with usage of $80 \%$ of energy in each stroke.

a)

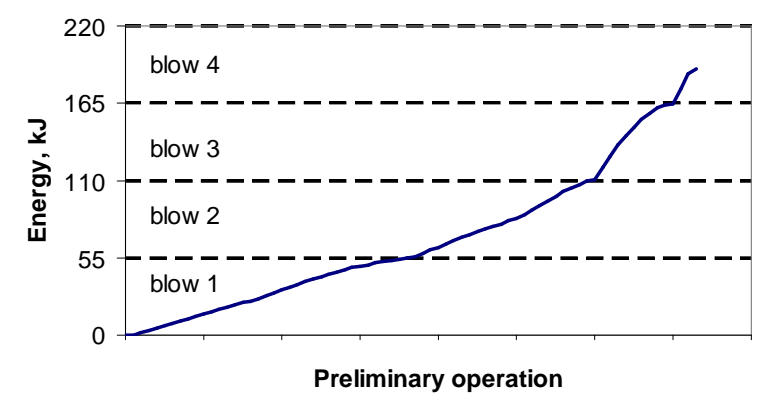

b)

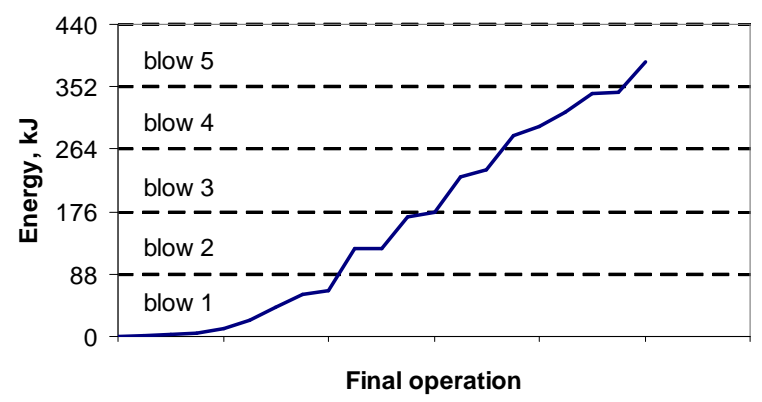

Figure 7. Energy consumption in: a) preliminary forging operation, b) final forging operation.

It results from calculations that for manufacturing of a finished forming (final operation in die impression) it is necessary to use larger amount of energy than it was assumed. At the assumed size of the hammer two strokes were planned, however, it results from calculations that at least five strokes should be used of relatively large machine energy. 


\subsection{Forging process on the press}

Another variant which underwent analysis was forming on the press. It was assumed that hydraulic press of constant velocity of stroke movement $300 \mathrm{~mm} / \mathrm{s}$ will be used. It was also assumed that, according to the designed technology, the drop forging will be forged in three operations: upsetting, preliminary forging in initial die, final forging after preform reheating.

Deformed material in the following forging operations on the hydraulic press of billet heated to the temperature equal $410^{\circ} \mathrm{C}$ is shown in Fig. 8 and Fig. 9. The shape of the product in particular operations is proper. Overlapping and infilling of the impression were not observed, which is presented in details in Fig. 10. This means that the process and the preform shape were properly designed.

a)

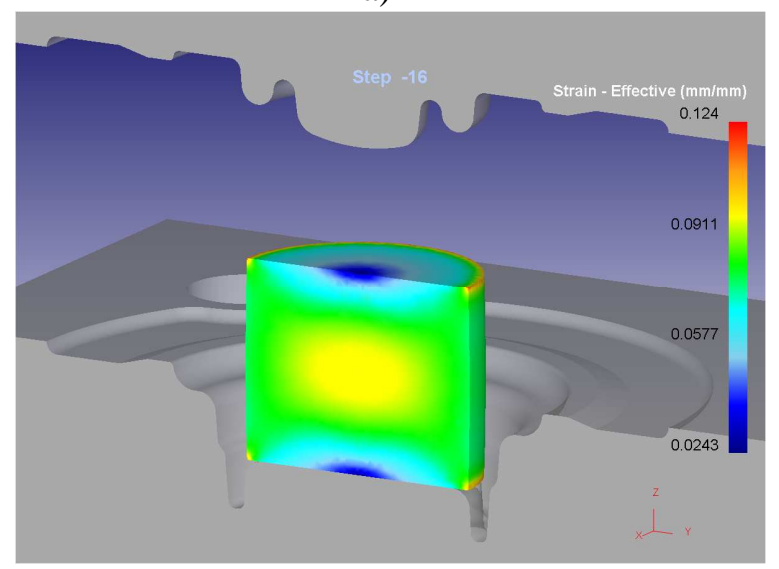

b)

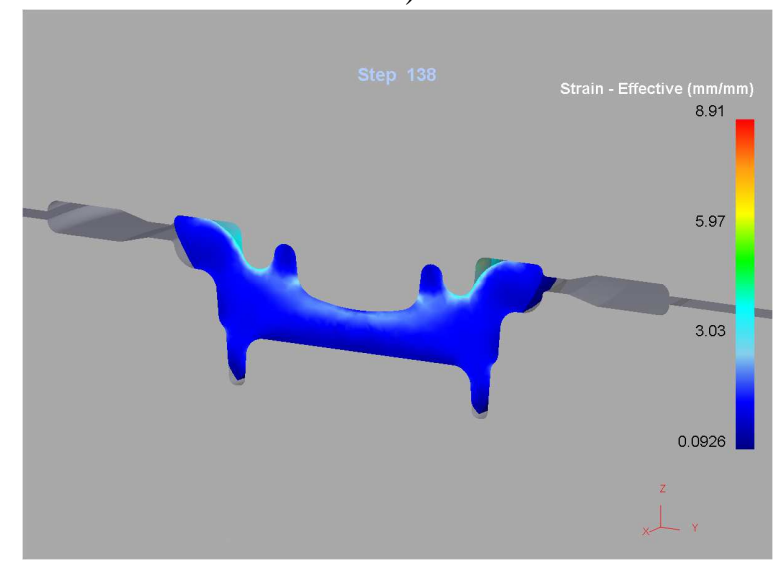

Figure 8. Beginning (a) and end (b) of preliminary forging operation in initial impression together with strains distribution - axial section.

a)

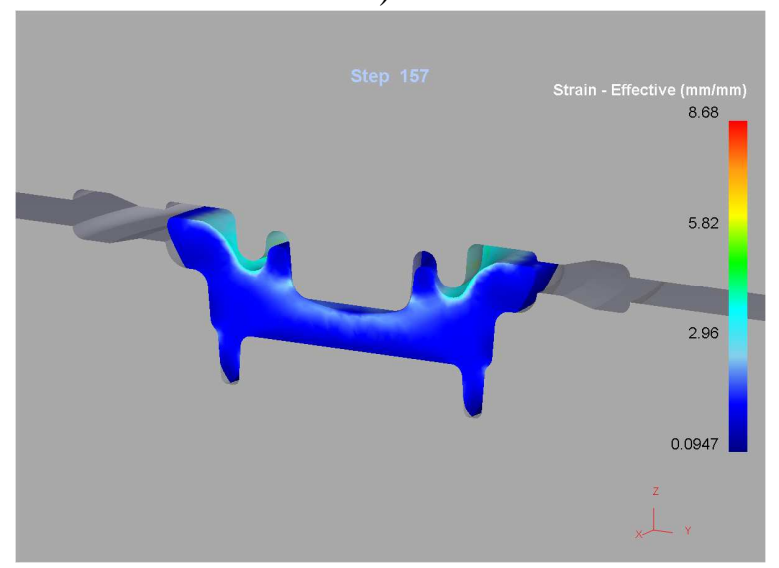

b)

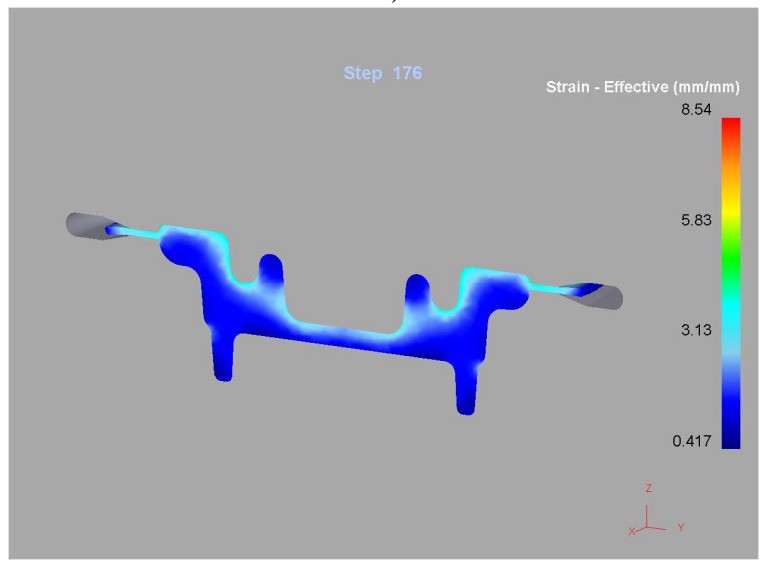

Figure 9. Beginning (a) and end (b) of final forging operation in die impression together with strains distribution - axial section. 
a)

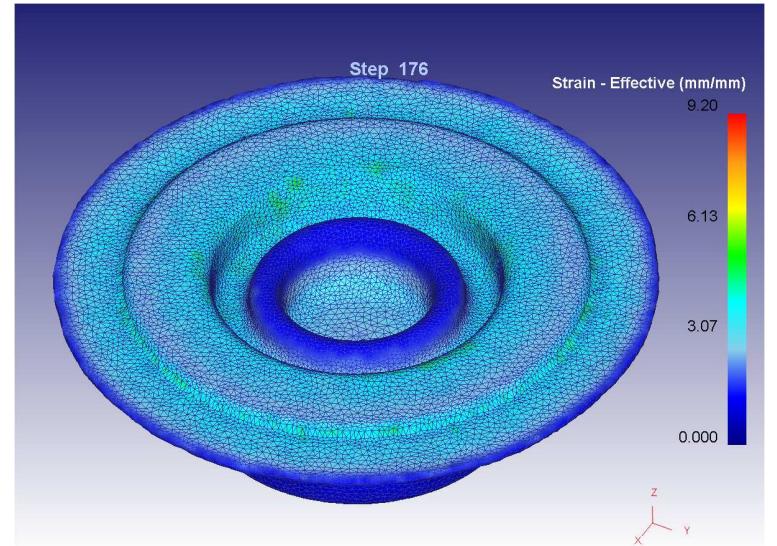

b)

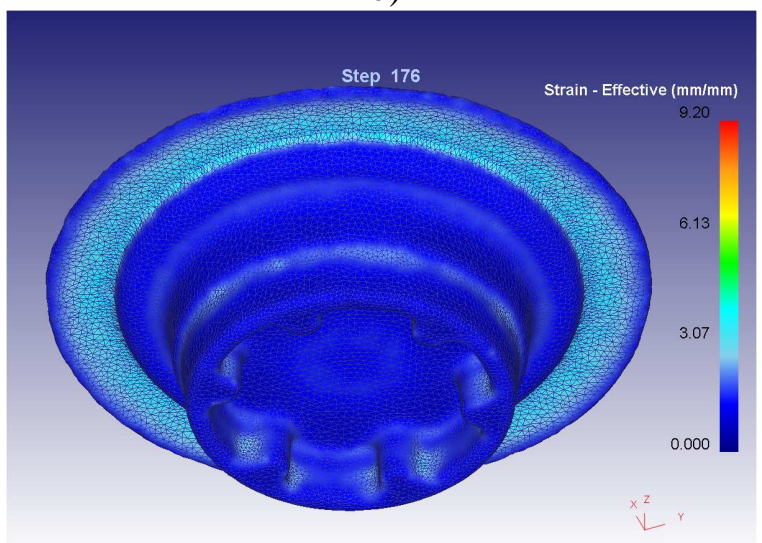

Figure 10. Drop forging obtained in simulation of the forging process on the press at billet heating to the temperature $410{ }^{\circ} \mathrm{C}$ : a) view from the top, b) view from the bottom.

Distribution of temperatures at the end of preliminary forging operation and final forging operation is shown in Fig. 11. In the first operation, inconsiderable increase of temperature in some areas of the drop forging can be observed. It is, however, not large; the temperature of the whole volume constitutes within the scope $410^{\circ} \mathrm{C} \div 442^{\circ} \mathrm{C}$. In die forging operation the largest increase of the temperature was observed in flash, where the temperature slightly increases $500^{\circ} \mathrm{C}$. In the rest of the forging the temperature reaches the value within the scope $395^{\circ} \mathrm{C} \div 440^{\circ} \mathrm{C}$. This discrepancy should be considered as a small one. On this basis it should be considered that concerning temperature distribution in the drop forging, forging conditions on the hydraulic press at assumed slide velocity are very favorable.

a)

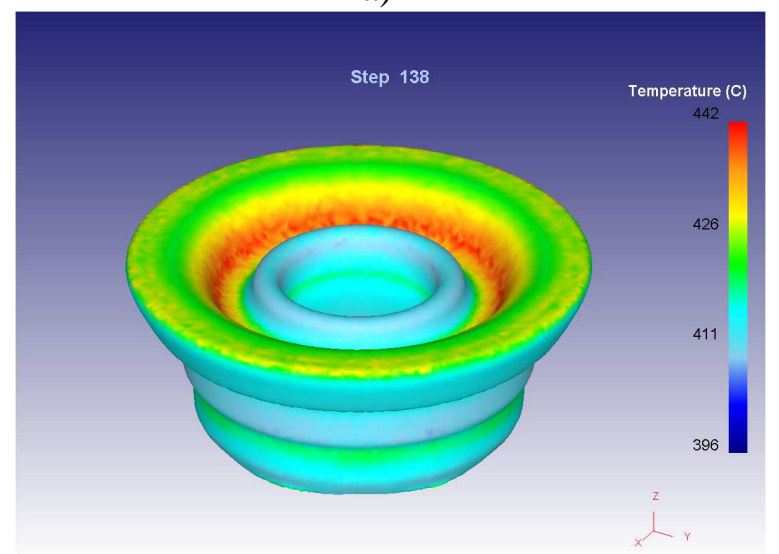

b)

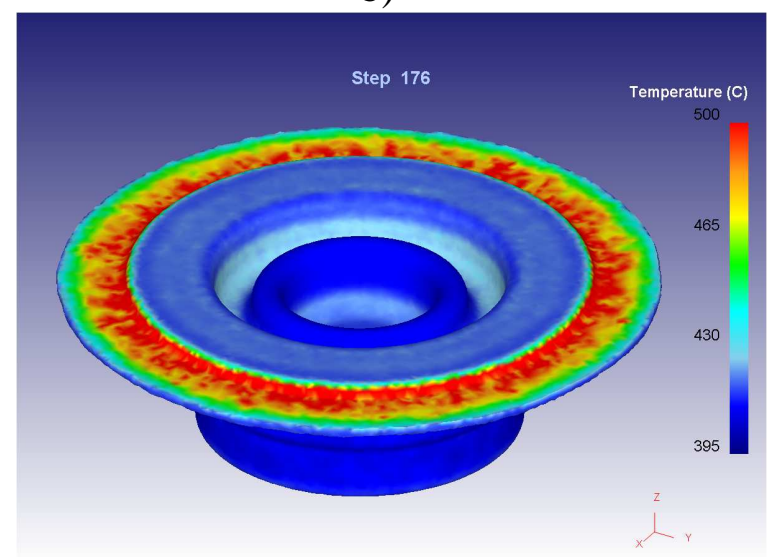

Figure 11. Distribution of temperatures in drop forging at the end of: a) preliminary forging operation, b) final forging operation.

Distribution of cracking criterion according to Cockroft-Latham is shown in Fig. 12. It is very similar to the one obtained in simulation of the forging process on hammer. Yet, the values in the case of forging on the press are smaller than in forging on hammer, which is 
favorable in the aspect of cracks appearance. The largest values are present on the flash external circumference, where cracks can be expected. In the rest of the forging C-L integral reaches the biggest value in the upper part and in the lower bulges.

a)

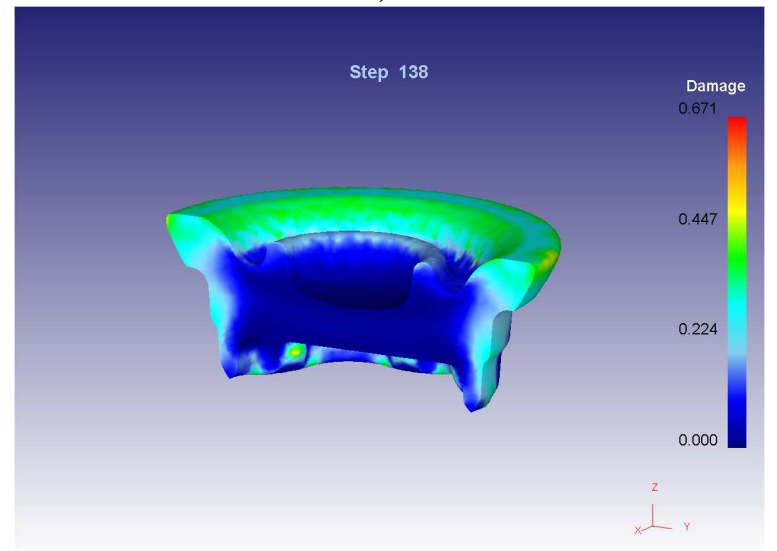

b)

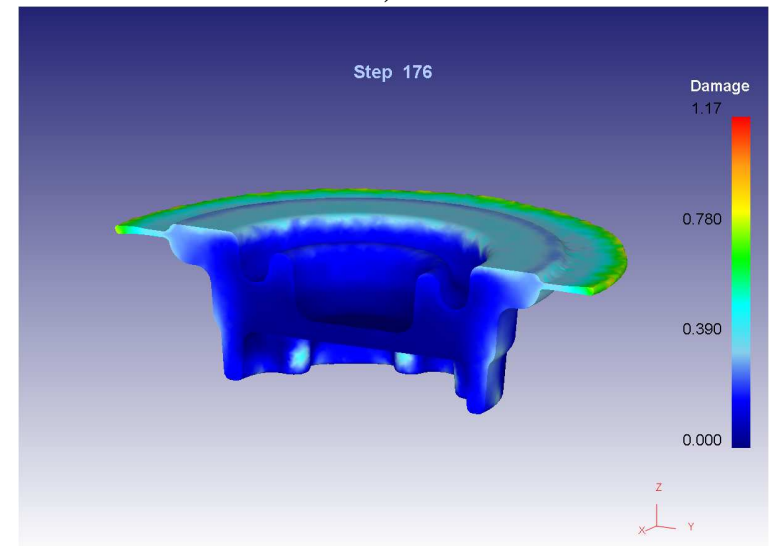

Figure 12. Distribution of Cockroft-Latham integral value in the drop forging at the end of:

a) preliminary operation, b) final operation.

The force course in the following forging operations on the hydraulic press at material heating temperature equal $410^{\circ} \mathrm{C}$ is shown in Fig. 13. As it can be seen in particular operations the force needed for material deformation increases. It equals $2.60 \mathrm{MN}$ and $31.06 \mathrm{MN}$ for preliminary and final forging operations respectively. As it can be seen, the last operation requires large force which is connected with the necessity of guaranteeing appropriate forging device. There exists a large difference between forging force in preliminary and final operations. Hence, test can be made to redesign the initial impression in such a way that the initial forging shape will be closer to the finished product. Such a solution will cause the increase of the forging force in the initial impression and decrease of the forging force in die impression at the same time. This will lower the requirements concerning the forging machine, and, apart from that, it will reduce discrepancy in dies (durability) load.

a)

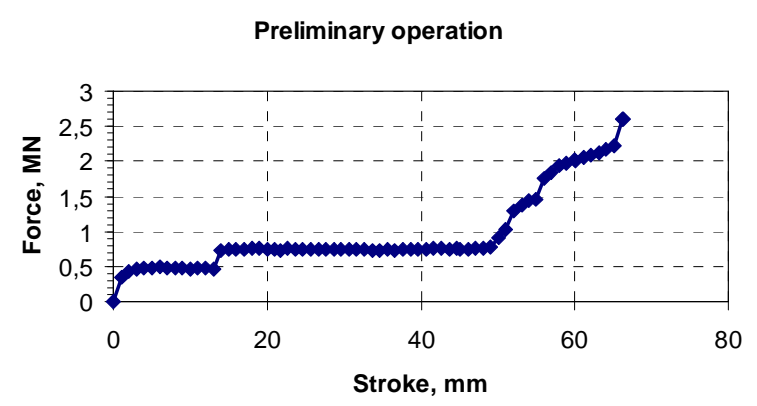

b)

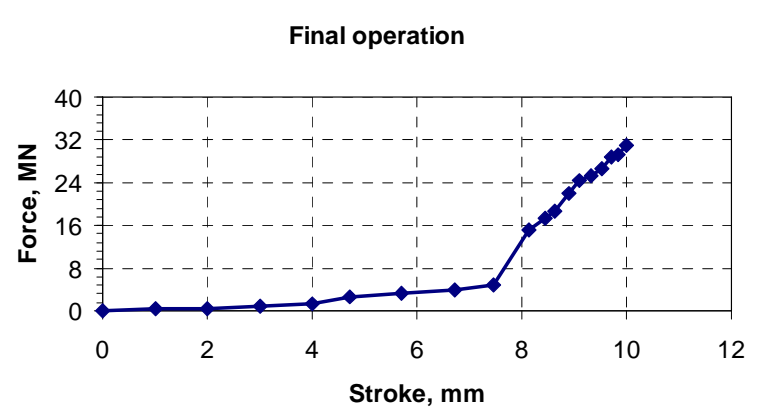

Figure 13. Course of forming force in the function of tool movement for: a) preliminary operation, b) final operation on hydraulic press. 


\section{CONCLUSIONS}

On the basis of conducted analysis the following conclusions were drawn:

1. Both analyzed forging processes, i.e. forging on the hammer and forging on the press guarantee obtaining of finished part of a proper shape.

2. The analysis of Cockroft-Latham damage criterion showed that in both analyzed variants of the process the largest risk of cracks (apart from flash) is present in the area of external part of the forging flange. In the forging process on the hammer the forming conditions are worse and this fault presence is more probable.

3. Calculations results concerning the forging process on the hammer show the presence of areas in the drop forging of too high temperature. Difficulties in estimating calculations precision (description in the paper) impose the necessity of structure and resistance properties verification in drop forgings obtained in industrial tests.

4. Forging process on the press is characterized by favorable distribution of temperature. A large increase of this parameter in the drop forging volume was not observed, which is connected with certain equilibrium between heat generated in the result of friction and strain and heat transmitted on the surface of contact between deformed material and tools and the environment.

5. Positive results of theoretical verification of the designed technology justify the purposefulness of conducted experimental research concerning die forging of the hub forging from AZ80 magnesium alloy.

\section{Acknowledgements}

Financial support of Structural Funds in the Operational Programme - Innovative Economy (IE OP) financed from the European Regional Development Fund - Project "Modern material technologies in aerospace industry", Nr POIG.01.01.02-00-015/08-00 is gratefully acknowledged.

\section{REFERENCES}

[1] Wu Y.J., Yang H., Sun Z. C., Fan X. G., "Simulation on influence of local loading conditions on material flow during rib-web components forming". China Mech. Eng. 17, 12-15, 2006.

[2] Aghion E., Bronfin B., Eliezer D., "The role of the magnesium industry in protecting the environment". Journal of Materials Processing Technology 117, 381-385, 2001.

[3] Wang Q., Zhang Z., Zhang X., Li G., " New extrusion process of Mg alloy automobile wheels". Trans. Nonferrous Met. Soc. China 20, 599-603, 2010.

[4] Gontarz A., Dziubinska A., Okon L., "Determination of friction coefficient at elevated temperatures for some Al, Mg and Ti alloys". Archives of Metallurgy and Materials 56, 
379-384, 2011.

[5] Juan L., Zhenshan C., "Hot forging process design and parameters determination of magnesium alloy AZ31B spur bevel gear". Journal of Materials Processing Technology 209, 5871-5880, 2009.

[6] Cockcroft M. G., Latham D. J., "Ductility and the workability of metals". Journal of the Institute of Metals 96, 33-39, 1968.

[7] Zhao Z., Zhuang X., Xie X., "An improved ductile fracture criterion for fine-blanking process". J. Shanghai Jiaotong Univ. (Sci.) 13, 702-706, 2008. 